\title{
Progress Towards Meningitis Prevention in the Conjugate Vaccines Era
}

Cristina Aparecida Borges Laval ${ }^{1}$, Fabiana Cristina Pimenta ${ }^{2}$, João Guimarães de Andrade ${ }^{2}$, Soraya S. Andrade ${ }^{3}$, and Ana Lucia S. S. de Andrade ${ }^{2}$
Secretariat of Health ${ }^{1}$, Municipality of Goiânia, Institute of Tropical Pathology and Public Health, Federal University of Goiás ${ }^{2}$, Goiânia, GO; Division of Infectious Diseases, Federal University of São Paulo ${ }^{3}$, São Paulo,SP, Brazil

Acute bacterial meningitis is an important cause of morbidity and mortality among children less than five years old. Haemophilus influenzae, Streptococcus pneumoniae and Neisseria meningitidis are the most important agents of bacterial meningitis in developing countries. The development of the conjugate vaccines in the beginning of the 90 's, especially type $b \mathrm{H}$. influenzae (Hib), and more recently the heptavalent pneumococcal and the serogroup $\mathrm{C}$ meningococcal vaccines, have contributed directly to changes in the epidemiological profile of these invasive diseases (direct effect) and of their carriage status (indirect effect). We review the impact of the Hib conjugate vaccine in Latin American countries, where this vaccine has been implemented, and the potential of pneumococcal and meningococcal conjugate vaccines for the reduction of meningitis worldwide. We also address constraints for the development and delivery of these vaccines and review new candidate state-of-the-art vaccines. The greatest challenge, undoubtedly, is to implement these vaccines worldwide, especially in the developing regions.

Key Words: Conjugate vaccines, Hib conjugate vaccine, pneumococcal conjugate vaccine, meningococcal conjugate vaccine, impact of Hib conjugate vaccine.

Acute bacterial meningitis is an important cause of morbidity among children, especially in developing countries [1,2]. Despite the increasing availability of potent antimicrobials and sophisticated intensive care units, mortality rates due to bacterial meningitis still reach high levels, leading to significant neurological sequelae $[3,4]$.

The advent of the conjugate vaccines during the last decade was a remarkable achievement, launching a new era in the history of modern vaccinology. In contrast to the first generation of the

Received on 12 April 2003; revised 27 September 2003. Address for correspondence: Dr.Ana Lucia S. S. de Andrade. Instituto de Patologia Tropical e Saúde Pública - UFG. Rua Delenda R Melo, S/N, Setor Universitário. Goiânia, Brasil. Zip code: 74 605-050. E-mail: ana@iptsp.ufg.br. Phone/Fax: + 5562-202-7942.

The Brazilian Journal of Infectious Diseases 2003;7(5):315-324 (C) 2003 by The Brazilian Journal of Infectious Diseases and Contexto Publishing. All rights reserved. purified polysaccharide vaccines, the conjugate vaccines produce a $\mathrm{T}$-dependent response and result in the development of an immunological memory, leading to clinical protection in children less than 2 years old $[5,6]$. This age group is at high risk for invasive diseases caused by the three most important agents of bacterial meningitis: Haemophilus influenzae, Streptococcus pneumoniae and Neisseria meningitidis [1].

The development of a conjugate vaccine against type b H. influenzae (Hib) in the early 1990's, and its implementation for routine immunization, have contributed directly to changes in the epidemiological profile of the invasive diseases caused by Hib in some developed countries, especially meningitis $[7,8]$. More recently, pneumococcal heptavalent conjugate vaccine and serogroup $\mathrm{C}$ meningococcal conjugate vaccine were licensed for commercial use, while the 9 to 11 valent pneumococcal vaccines are at an advanced stage of field trials in many countries [9-13]. 


\section{H. influenzae Type b Vaccine}

Finland, Canada, Iceland, United States, United Kingdom, Israel and Australia were the first countries to use the Hib vaccine on a large scale at the end of the 1980 's and the beginning of the 90's. Heath, in a review about the efficacy of Hib vaccine in these countries, indicated a spectacular reduction of invasive disease incidence due to H. influenzae b [14]. In the USA, Adams et al. observed a decrease of $82 \%$ in $\mathrm{H}$. influenzae meningitis between 1985 and 1991 based on national surveillance data [7]. Dawson et al. [15], in a retrospective study, detected a fall in the number of meningitis cases by H. influenzae b, from $73 \%$ to $69 \%$, with the polysaccharide vaccine, and to $16 \%$, within a 5-yearperiod after the introduction of the conjugate vaccine.

In Latin America (LA), the conjugate vaccine was first introduced into Uruguay in 1994, followed by Costa Rica and Chile, and it is currently incorporated into the immunization programs of almost all LA countries [16]. In Uruguay, the incidence rate of Hib meningitis fell from 15.6 to 0.03 per $100,000,2$ years after the introduction of this vaccine [17]. In Brazil, this vaccine was first used in Curitiba (southern Brazil) in 1996, and after a year of routine use, a $72 \%$ reduction was observed in the incidence of meningitis [18]. Nationwide immunization in Brazil began in mid 1999, and after 2 years, Simões et al. [19], in a prospective population surveillance carried out in Goiás State (Central Brazil), demonstrated a $78 \%$ decline in the risk of meningitis by $H$. influenzae $\mathrm{b}$ among children under 5 years of age. Furthermore, studies conducted in Brasília and Salvador detected a reduction of meningitis cases of $80 \%$ and $69.9 \%$, respectively, after the first year of the initiation of $\mathrm{Hib}$ vaccination [20,21]. The impact of Hib vaccine on the reduction of meningitis in Latin America countries after the introduction of the Hib vaccine in this region ranged from $40.0 \%$ to $95.6 \%$, depending on the timeperiod of assessment (Table 1) [18-26].

The significant decline of bacterial meningitis caused by Hib was due not only to the direct effect of this vaccine on individual protection, but also to the reduction of colonization of the nasopharynx [27-31], decreasing the transmission of Hib and therefore the incidence of meningitis by $H$. influenzae $b$ in vaccine recipients as well as in non-vaccinated children (indirect effect of the vaccine - herd immunity) [32].

Despite the availability of the Hib conjugate vaccine and its impressive impact on invasive diseases in countries where it has been implemented, about 132 million children have not been treated with this vaccine, most of them in poor countries in Africa and Asia. A map (Figure 1) shows the current geography of Hib vaccine implementation in the world [33].

Important obstacles have hampered the introduction of this vaccine into the African and Asian continents. Information about the production, the estimated costs, the use of the vaccine on a large scale, as well as the safety and efficacy of this vaccine are essential in these regions. Various investigations have shown cost to be the most critical issue to introduce the vaccination in these countries, whereas safety and efficacy, although significant, are less relevant. The unfavorable economic and financial situation in many countries in Africa have impeded increases in per capita spending on health, making it unfeasible to introduce the Hib vaccine [34]. Most countries in Africa have limited medical and laboratory support, making the proper identification of etiological agents involved in invasive diseases difficult. Moreover, other complex health problems, including tuberculosis, malaria, HIV and meningococcal disease, compete against $H$. influenzae $\mathrm{b}$ for priority. The public health policy makers need to be aware of the magnitude and the social costs of the Hib diseases, and they should maximize efforts to incorporate this vaccine into routine health services $[35,36]$.

\section{Pneumococcal Conjugate Vaccine}

In comparison with Hib, Streptococcus pneumoniae is involved in a broader range of disorders, including invasive (pneumonia and meningitis), and non-invasive (acute otitis media and sinusitis) diseases. It also contributes to the highest levels of mortality and morbidity in the world, especially in children under 5 years old [37-39]; at least 1.2 million deaths occur annually due to pneumonia, $39 \%$ are children less than 5 years, with 100,000 to 500,000 deaths by pneumococcal meningitis [37]. 
Table 1. Impact of Haemophilus influenzae b conjugate vaccine on meningitis in Latin American countries

\begin{tabular}{|c|c|c|c|c|c|c|}
\hline Country & Author, year & $\begin{array}{c}\text { Vaccine } \\
\text { introduction }\end{array}$ & Age group & $\begin{array}{c}\text { Timing after Hib } \\
\text { vaccine introduction }\end{array}$ & $\begin{array}{l}\text { Coefficients } \times 10^{5} \\
\text { pre/post vaccine }\end{array}$ & $\begin{array}{l}\% \text { Decrease } \\
\text { post vaccine }\end{array}$ \\
\hline Cuba & Dickinson et al. 2001 [23] & 1999 & $<5$ years & 1 year & $13.6 / 7.6$ & 52.8 \\
\hline Colombia & Agudelo et al. 2000 [24] & 1998 & $<1$ year & 1 year & - & 40.0 \\
\hline \multirow[t]{2}{*}{ Uruguay } & Ruocco et al. 1999 [17] & 1994 & $<5$ years & 2 years & $15.6 / 2.7$ & 82.7 \\
\hline & Landaverde et al.1999 [25] & 1994 & All ages & 6 months & - & 95.6 \\
\hline Chile & Diaz et al. 2001 [26] & 1996 & $<5$ years & 2 years & $36.4 / 9.9$ & 72.7 \\
\hline \multirow[t]{4}{*}{ Brazil } & $\begin{array}{l}\text { Takemura \& } \\
\text { Andrade } 2001[18]\end{array}$ & 1996 & $<5$ years & 1 year & $35.4 / 9.7$ & 72.6 \\
\hline & Freitas 2000 [20] & 1999 & $<5$ years & 1 year & - & 80.0 \\
\hline & Simões et al. 2002 [19] & 1999 & $<5$ years & 1 year & $10.8 / 2.3$ & 78.7 \\
\hline & Ribeiro et al. 2003 [21] & 1999 & $<5$ years & 1 year & $2.6 / 0.8$ & 69.0 \\
\hline
\end{tabular}

Source: Adapted from Simões 2002 [22].

${ }^{a}$ not reported.

${ }^{\mathrm{b}}$ metropolitan area of Santiago.

${ }^{c}$ incidence in non-exposed to vaccine.

dincidence in exposed to vaccine.

${ }^{\mathrm{e}}$ reference: Wenger et al 2000. 
Figure 1. [33]

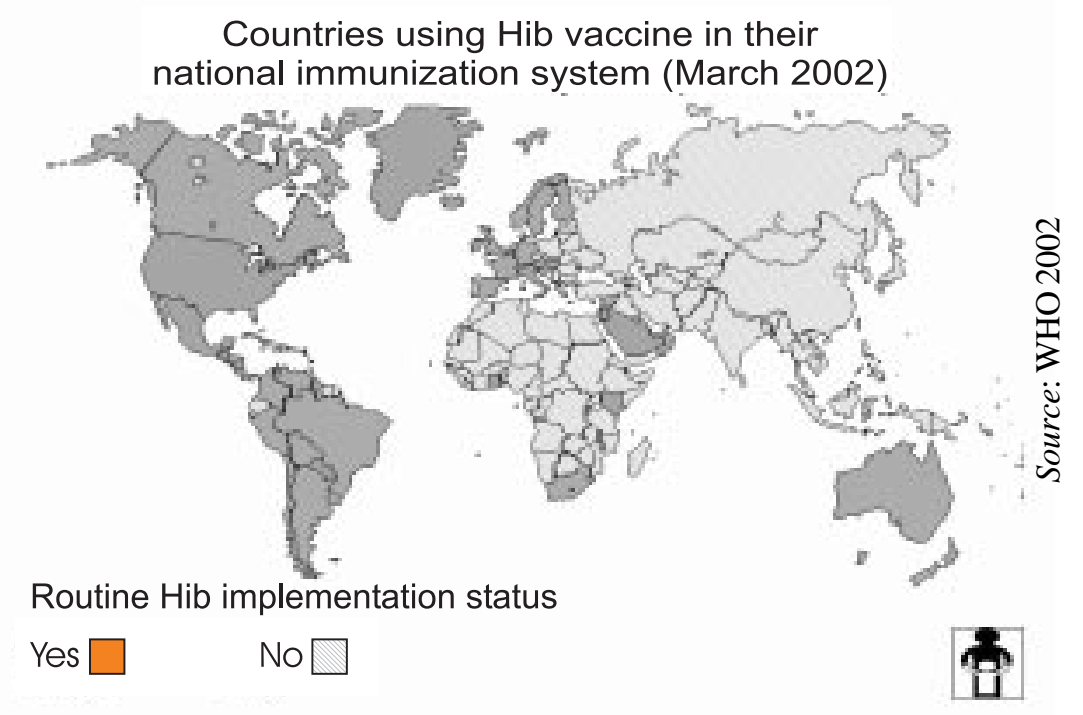

The success achieved by Hib immunization has stimulated the development of a pneumococcal conjugate vaccine. In February 2000 the Food and Drug Administration approved the use of a sevenvalent conjugate vaccine for American children under 2 years old. Among the 90 S. pneumoniae serotypes identified so far [40], the formulation of this vaccine contains only 7 serotypes $-4,6 \mathrm{~B}, 9 \mathrm{~V}, 14,18 \mathrm{C}, 19 \mathrm{~F}$ and $23 \mathrm{~F}$, but these are responsible for $70 \%$ to $90 \%$ of the invasive disease cases in children in the USA, Canada, Africa and Europe and are $70 \%$ of the pneumococci that cause acute otitis media in USA, Canada and Europe $[41,42]$. Clinical trials carried out with the 7-valent vaccine in USA have revealed high levels of protection against invasive pneumococcal disease, and another review found a $50 \%$ to $60 \%$ protection range against serotype specific pneumococcal otitis in Finland [43,44]. In Brazil, the heptavalent vaccine was licensed in February 2001 [45], but it has still not been added to the PNI (national program of immunizations) schedule. The 9-valent conjugate vaccine contains the 7-valent serotypes, as well as serotypes 1 and 5, and it has been evaluated by large-scale field trials in South Africa and Gambia
[46]. The 11-valent vaccine includes the 9-valent serotypes, as well as serotypes 3 and $7 \mathrm{~V}$, and it is currently under test in clinical trials in the Philippines, Israel, Argentina and Chile [13,38,47].

While the expected impact of the Hib conjugate vaccine is a reduction in meningitis cases, the pneumococcal vaccines are also expected to reduce pneumonia and acute otitis media cases, as well as carriage prevalence, which will significantly modify pneumococcal disease epidemiology [48-50]. Eskola and Anttila [19] have shown that in clinical trials with the 7-11 valent pneumococcal conjugate vaccines, the coverage against invasive disease, including meningitis, can reach $92 \%$. DiFabio et al. [51] estimated a 64.4\% serotype coverage (95\% confidence interval (CI: $60.7 \%-67.8 \%$ ) for meningitis with the use of the heptavalent pneumococcal vaccine in Brazil. Similar results were reported by Brandileone et al. [52], who found that the 7-valent vaccine would cover $61 \%$ (95\% CI: $57.0 \%-64.9 \%$ ) of the most prevalent meningitis serotypes in Brazil in children under 2 years old $(1,14,19 \mathrm{~A}, 19 \mathrm{~F}, 5,6 \mathrm{~A}$ and $6 \mathrm{~B})$. It is worthwhile emphasizing the high prevalence of serotypes 1 and 5 in Latin American countries, which are not included in the heptavalent vaccine. 
The efficacy of pneumococcal vaccine against meningitis needs to be better evaluated. So far, clinical trials conducted in California by the Kaiser group, and in Navajo children, did not find any case of meningitis in the vaccinated group; however, as the number of cases in the control group has not yet been reported $[48,53,54]$, it is probable that the efficacy of the heptavalent vaccine against pneumococcal meningitis would be better evaluated through meta-analyzes, which have the advantage of pooling to attain a higher sample size, increasing the power to detect significant differences between vaccinated and unvaccinated groups. Observational studies may also be conducted to assess the effectiveness of the pneumococcal vaccine during the vaccine post-licensure period.

Although there has been optimism concerning the impact of the $S$. pneumoniae conjugate vaccine, there are some restrictions against its incorporation into health services routine, including: (i) the high cost for implementation at a public health level, especially in the developing world, (ii) controversy about crossprotection against serotypes not contained in the vaccine, and (iii) the technical difficulties of having all pneumococcal serotypes in the same formulation. Consequently, alternative candidates to the pneumococcal vaccine have been tested for immunogenicity and safety, including protein vaccines. A large number of investigators have searched for proteins capable of inducing immunity to invasive and non-invasive pneumococcal infection. Pneumococcal surface proteins, including protein A (PspA), protein $\mathrm{C}$ (PspC), adhesin (PsaA) and pneumolysin, have been considered as alternatives to promote protective immunity in children $[55,56]$. These proteins can induce protection regardless of pneumococcal serotype; for example, PspA has been found in all isolates of $S$. pneumoniae [57]. According to the amino acids sequences, PspA can be classified into three families. Families 1 and 2 are the main ones, and are found in more than $98 \%$ of the PspA molecules [58,59]. Studies conducted in animal models have showed that PspA was the most efficacious protein for immunization against carriage, otitis media, pneumonia and sepsis. A synergistic effect has been detected when two proteins are associated. A combination of PspA and pneumolysin can induce a higher immunity to lung infections and probably against septicemia, when compared to PspA alone [55,60]. The relative protective capacities of several different pneumococcal proteins against sepsis, bacteremia, pneumonia, otitis media and carriage suggest that the association of different proteins optimizes protection against a broad variety of strains and diseases. Therefore, it is plausible that vaccines against $S$. pneumoniae composed of mixtures of polysaccharides and several protein antigens might be a better approach than a vaccine based on a single type.

\section{Meningococcal Conjugate Vaccine}

Meningococcal meningitis is an important public health problem worldwide, especially in sub-Saharan Africa, where it occurs as an endemic disease, with outbreaks every 2 years [61,62]. Neisseria meningitis isolates can be classified into 12 groups, based on chemically and antigenically distinct polysaccharide capsules, but only 5 groups are responsible for almost all meningococcal disease: A, B, C, Y and W135. Serogroup A is responsible for epidemic disease in subSaharan Africa and in developing countries in other regions. Serogroups B and C are responsible for most of the infections in developed countries, as well as in developing regions. The pattern of disease caused by serogroup B is typically hyperendemic or sporadic, in contrast to the endemic nature of serogroup A. In the United Kingdom, 32\% of the reports of invasive disease caused by $N$. meningitidis in 1996 were associated with serogroup C [6]. Meningococcal disease caused by serogroups Y and W135 is mainly found in the USA [62].

The polysaccharide vaccines against serogroups A and $\mathrm{C}$, widely used for many years with relative success in mass immunizations during outbreaks, are efficacious in older children and in adults, but are much less immunogenic in children under 5 years old [63]. The development and use of meningococcal conjugate vaccine is an alternative to polysaccharide vaccines. The conjugate vaccines for $N$. meningitidis are at 
several stages of development and clinical trials. Besides being more immunogenic than the polysaccharides, the meningococcal conjugate vaccines induce "herd immunity" [64]. Most of the efforts toward the development of meningitis conjugate vaccines first concentrated on serogroups $\mathrm{A}$ and $\mathrm{C}$, at the end of the 1980's. Studies conducted on children in Gambia and the United Kingdom showed good immunogenicity and tolerability for the bivalent conjugate vaccine A-C $[65,66]$. Recently, several clinical trials made with children and teenagers have confirmed the safety, immunogenicity and capacity to induce immunological memory of serogroup C meningococcal vaccine [67-70].

In Africa, an extensive project to wipe out epidemic meningitis has begun, based upon the utilization of two vaccines. One of them, a heptavalent product (DTPw, hepatitis $b$, Hib, meningococcal conjugate A-C), is to be used in the expanded program of immunization, and another product, a monovalent vaccine against meningococcus $\mathrm{A}$, will be used in the population from 1 to 29 years old [71]. Field trials with both vaccines are scheduled to begin soon.

The United Kingdom was the first country to include the conjugate vaccine against serogroup $\mathrm{C}$ in a routine immunization program, in November 1999. After the use of this vaccine in children and teenagers less than 19 years old, a strong reduction in serogroup $\mathrm{C}$ meningococcal disease was observed $[11,72,73]$. Recently, Trotter et al. [74] reported that, with a coverage of $89 \%$ vaccination, a reduction of $80 \%$ in the incidence of meningitis by serogroup $\mathrm{C}$ was detected and the number of deaths fell from 78 to 8 during the same time period.

Serogroup B meningococcus is an important problem in the Americas and Europe due to its high incidence in these regions, and no effective vaccine is available to date $[75,76]$. The development of a vaccine against serogroup $B$ is a more difficult task. The similarity between the polysaccharide structure of the bacterial capsule and carbohydrates naturally found in humans make this antigen auto-limited or poorly immunogenic. Furthermore, the use of this polysaccharide in a vaccine can stimulate the production of auto-antibodies $[77,78]$. An alternative approach to vaccine development is based on outermembrane vesicles. Although such vaccines induce an antibody response and protect against meningococcal disease, especially among children more than four years of age [79-82], they do not protect against several known heterologous strains [83]. On the other hand, many previously unrecognized proteins were identified and characterized during the genome sequencing of a virulent strain, MC58, of meningococcus B $[84,85]$. Some of these proteins induce bactericidal antibodies in serum against serogroup B meningococcus. Thus, there is a new potential vaccine candidate, which should be safe and capable of promoting strong homologous and heterologous protection against $N$. meningitidis B strains, although it is also likely to promote crossprotection against other serogroups.

\section{Final Remarks}

In this epidemiological scenario post-introduction of conjugate Hib vaccine into routine immunization programs, the greatest challenge is to improve the current surveillance systems. Considering the sharp decrease of invasive disease as well as the carriage status of Hib, more sensitive and specific diagnostic tools are essential to the early detection of the emergence of other $H$. influenzae serotypes, especially the non-typeable $H$. influenzae and also the $S$. pneumoniae, which could occupy the ecological niche left by Hib [86-89]. The monitoring of possible vaccine failure [90,91], the reemergence of cases of invasive disease by Hib, despite adequate levels of vaccine coverage, and the antimicrobial susceptibility of $H$. influenzae, including the "non-b" strains and $S$. pneumoniae, are also imperative in this post-vaccine era [92-98].

While waiting for a more effective vaccine against all meningococcus groups, the best strategy for meningococcal meningitis prevention is prompt largescale mass vaccination during the epidemic period. Studies carried out in African countries have suggested that an efficient surveillance system, especially for the detection of meningococcal meningitis outbreaks, might guide appropriate control measures, such as a mass 
catch-up vaccination campaign, to timely decrease the number of cases of the disease [99].

Incorporation of new epidemiological information might be attained with the use of molecular typing techniques for the characterization of the invasive and colonizing serotypes, allowing systematic evaluations of the Hib vaccine and of the forthcoming conjugate vaccines of $S$. pneumoniae and $N$. meningitidis, when they become widely available and implemented.

\section{Acknowledgements}

This investigation was sponsored by the Division of Vaccines and Immunization of the Pan American Health Organization, World Health Organization, the Bill and Melinda Gates Children's Vaccine Program, the Brazilian Council for Research and Development/ CNPq (Research Grant \# 520399/00-5), and the Secretariat of Health of Goiânia Municipality.

\section{References}

1. Hausdorff W. Haemophilus, meningococcus and pneumococcus: Comparative epidemiologic patterns of disease. Int J Clin Pract Suppl 2001;(118):2-4.

2. Peltola H. Worldwide Haemophilus influenzae type b disease at the beginning of the 21 st century: Global analysis of the disease burden 25 years after the use of the polysaccharide vaccine and a decade after the advent of conjugates. Clin Microbiol Rev 2000; 13:302-17.

3. Oostenbrink R., Maas M., Moons K.G., Moll H.A. Sequelae after bacterial meningitis in childhood. Scand J Infect Dis 2002;34:379-82.

4. Quagliarello V.J., Scheld W.M. Treatment of bacterial meningitis. N Engl J Med 1997;336:708-16.

5. Ada G.Vaccines and vaccination. N Engl J Med 2001;345:1042-53.

6. Goldblatt D. Recent developments in bacterial conjugate vaccines. J Med Microbiol 1998;47:563-7.

7. Adams W.G., Deaver K.A., Cochi S.L., et al. Decline of childhood Haemophilus influenzae type b (Hib) disease in the Hib vaccine era. JAMA 1993;269:221-6.

8. Levine O.S., Schwartz B., Pierce N., Kane M. Development, evaluation and implementation of Haemophilus influenzae type b vaccines for young children in developing countries: Current status and priority actions. Pediatr Infect Dis J 1998; 17:S95-113.
9. Eskola J., Anttila M. Pneumococcal conjugate vaccines. Pediatr Infect Dis J 1999; 18:543-51.

10. FDA. Food and Drugs Administration. First pneumococcal vaccine approved for infants and toddlers. Available: http://www.fda.gov/ bbs/topics/ NEWS/NEW00716.html. Accessed 28 November 2001.

11. Salisbury D. Introduction of a conjugate meningococcal type $\mathrm{C}$ vaccine programme in the UK. J Paediatr Child Health 2001;37:S34-6.

12. Shinefield H. Pneumococcal conjugate vaccine and ongoing lessons. Int J Clin Pract Suppl 2001;(118):23-5.

13. World Health Organization. Report of a meeting on priorities for pneumococcal and Haemophilus influenzae type b (Hib) vaccine development and introduction. Geneva, February 2000. Available: $\underline{\text { http:/ }}$ /www.who.int/vaccines-documents/ DocsPDF01/ www530.pdf. Accessed 20 November 2002.

14. Heath P.T. Haemophilus influenzae type b conjugate vaccines: A review of efficacy data. Pediatr Infect Dis J 1998; 17(9 Suppl):S117-22.

15. Dawson K.G., Emerson J.C., Burns J.L. Fifteen years of experience with bacterial meningitis. Pediatr Infect Dis J 1999; 18:816-22.

16. Di Fabio J.L., de Quadros C. Considerations for combination vaccine development and use in the developing world. Clin Infect Dis 2001;33Suppl 4: S340-5.

17. Ruocco G., Curto S., Savio M., et al. Vaccination against Haemophilus influenzae type b in Uruguay: Experience and impact. Rev Panam Salud Publica 1999;5:197-9.

18. Takemura N.S., Andrade S.M. Meningite por Haemophilus influenzae tipo b em cidades do estado do Paraná, Brasil. J Pediatr (Rio J) 2001;77:387-92.

19. Simões L.L.P., Andrade A.L.S.S., Laval C.A.B.P., et al. Effectiveness of $H$. influenzae b conjugate vaccine on meningitis in Central Brazil. In: International Journal of Epidemiology. XVI IEA World Congress of Epidemiology of the International Epidemiology Association. Oxford, 2002.

20. Freitas H. Meningite por Haemophilus influenzae b no Distrito Federal. Aspectos epidemiológicos e impacto após introdução da vacina. In: Dissertação para obtenção de título de mestre em Saúde Coletiva. 2000. Universidade de Brasília: Brasília.

21. Ribeiro G.S., Reis J.N., Cordeiro S.M., et al. Prevention of Haemophilus influenzae type b (Hib) meningitis and emergence of serotype replacement with type a strains after introduction of Hib immunization in Brazil. J Infect Dis 2003; $187: 109-16$.

22. Simões L.L.P. Avaliação da vacina conjugada do Haemophilus influenzae b: aspectos epidemiológicos e impacto nas meningites em Goiás. In: Dissertação para obtenção de título de mestre. 2002. Universidade Federal de Goiás: Goiânia. 
23. Dickinson F.O., Perez A.E., Galindo M.A., Quintana I. Impact of vaccination against Haemophilus influenzae type b in Cuba. Rev Panam Salud Publica 2001;10:169-73.

24. Agudelo C.I., Munoz N., De la Hoz F. Rapid assessment of the impact of Haemophilus influenzae vaccine serotype b in Colombia. Public Health Laboratories. Rev Panam Salud Publica 2000;8:181-4.

25. Landaverde M., Di Fabio J.L., Ruocco G., et al. Introduction of a conjugate vaccine against $\mathrm{Hib}$ in Chile and Uruguay. Rev Panam Salud Publica 1999;5:200-6.

26. Diaz J.M., Catalan L., Urrutia M.T., et al. Trends of etiology of acute bacterial meningitis in Chilean children from 1989 to 1998 . Impact of the anti- $H$ influenzae type $b$ vaccine. Rev Med Chil 2001;129:719-26.

27. Barbour M.L., Mayon-White R.T., Coles C., et al. The impact of conjugate vaccine on carriage of Haemophilus influenzae type b. J Infect Dis 1995;171:93-8.

28. Adegbola R.A., Mulholland E.K., Secka O., et al. Vaccination with a Haemophilus influenzae type $\mathrm{b}$ conjugate vaccine reduces oropharyngeal carriage of $H$. influenzae type b among Gambian children. J Infect Dis 1998; $177: 1758-61$.

29. Forleo-Neto E., de Oliveira C.F., Maluf E.M., et al. Decreased point prevalence of Haemophilus influenzae type b (Hib) oropharyngeal colonization by mass immunization of Brazilian children less than 5 years old with hib polyribosylribitol phosphate polysaccharidetetanus toxoid conjugate vaccine in combination with diphtheria-tetanus toxoids-pertussis vaccine. J Infect Dis 1999; $180: 1153-8$.

30. Murphy T.V., Pastor P., Medley F., et al. Decreased Haemophilus colonization in children vaccinated with Haemophilus influenzae type b conjugate vaccine. J Pediatr 1993; 122:517-23.

31. Takala A.K., Eskola J., Leinonen M., et al. Reduction of oropharyngeal carriage of Haemophilus influenzae type b (Hib) in children immunized with an Hib conjugate vaccine. J Infect Dis 1991;164:982-6.

32. Moulton L.H., Chung S., Croll J., et al. Estimation of the indirect effect of Haemophilus influenzae type b conjugate vaccine in an American Indian population. Int J Epidemiol 2000;29:753-6.

33. World Health Organization. Vaccines \& Surveillance. Available: http://www. who.int/vaccines-surveillance/ graphics/htmls/HibVacUseMar02.htm Accessed 20 November 2002.

34. World Health Organization. Expert review of a tool for rapidly assessing Haemophilus influenzae type b (Hib) disease burden. Geneva, October 2000. Available: http:/ /www.who.int/ vaccines-documents/DocsPDF01/ www604.pdf. Accessed 14 November 2002.
35. Peltola H. Burden of meningitis and other severe bacterial infections of children in Africa: Implications for prevention. Clin Infect Dis 2001;32:64-75.

36. Wenger J.D., DiFabio J., Landaverde J.M., et al. Introduction of Hib conjugate vaccines in the nonindustrialized world: Experience in four 'newly adopting' countries. Vaccine 1999; 18:736-42.

37. Greenwood B. The epidemiology of pneumococcal infection in children in the developing world. Philos Trans R Soc Lond B Biol Sci 1999;354:777-85.

38. Mulholland K. Strategies for the control of pneumococcal diseases. Vaccine 1999;17Suppl 1:S79-84.

39. Obaro S.K., Monteil M.A., Henderson D.C. The pneumococcal problem. BMJ 1996;312:1521-5.

40. Hinrichsen J. Six newly recognized types of Streptococcus pneumoniae. J Clin Microbiol 1995;33:2759-62.

41. Hausdorff W.P., Bryant J., Paradiso P.R., Siber G.R. Which pneumococcal serogroups cause the most invasive disease: Implications for conjugate vaccine formulation and use: I. Clin Infect Dis 2000;30:100-21.

42. Hausdorff W.P., Bryant J., Kloek C., et al. The contribution of specific pneumococcal serogroups to different disease manifestations: Implications for conjugate vaccine formulation and use: II. Clin Infect Dis 2000;30:122-40.

43. Black S., Shinefield H., Fireman B., et al. Efficacy, safety and immunogenicity of heptavalent pneumococcal conjugate vaccine in children. Northern California Kaiser Permanente Vaccine Study Center Group. Pediatr Infect Dis J 2000; 19:187-95.

44. Eskola J., Kilpi T., Palmu A., et al. Efficacy of a pneumococcal conjugate vaccine against acute otitis media. N Engl J Med 2001;344:403-9.

45. ANVISA. Agência Nacional de Vigilância Sanitária Ministério da Saúde do Brasil. Available: http:// www.anvisa.br. Accessed 25 October 2002.

46. Klugman K.P., Madhi S.A., Huebner R.E., et al. A trial of a 9-valent pneumococcal conjugate vaccine in chiuldren with and those without HIV infection. N Engl Med 2003;349(14):1341-8.

47. Klugman K.P. Efficacy of pneumococcal conjugate vaccines and their effect on carriage and antimicrobial resistance. Lancet Infect Dis 2001;1:85-91.

48. Black S.B., Shinefield H.R., Hansen J., et al. Post licensure evaluation of the effectiveness of seven valent pneumococcal conjugate vaccine. Pediatr Infect Dis J 2001;20:1105-7.

49. Dagan R., Sikuler-Cohen M., Zamir O., et al. Effect of a conjugate pneumococcal vaccine on the occurrence of respiratory infections and antibiotic use in daycare center attendees. Pediatr Infect Dis J 2001;20:951-8. 
50. Dagan R., Melamed R., Muallem M., et al. Reduction of nasopharyngeal carriage of pneumococci during the second year of life by a heptavalent conjugate pneumococcal vaccine. J Infect Dis 1996;174:1271-8.

51. Di Fabio J.L., Castaneda E., Agudelo C.I., et al. Evolution of Streptococcus pneumoniae serotypes and penicillin susceptibility in Latin America, Sireva-Vigia Group, 1993 to 1999. PAHO Sireva-Vigia Study Group. Pan American Health Organization. Pediatr Infect Dis J 2001;20:959-67.

52. Brandileone M.C., Andrade A.L.S.S., DiFabio J.L., et al. Appropriateness of a pneumococcal conjugate vaccine in Brazil: Potential impact of age and clinical diagnosis, with emphasis on meningitis. J Infect Dis 2003; $187: 1206-12$.

53. O’Brien K.L., Bronsdon M.A., Carlone G.M., et al. Effect of a 7-valent pneumococcal conjugate vaccine on nasopharyngeal (NP) carriage among Navajo and White Mountain Apache (N/WMA) infants (abstract 1463). In: Abstracts of the Society for Pediatric Research, Baltimore, MD, USA. 2001.

54. O’Brien K.L., Moulton L., Reid R., et al. Invasive disease efficacy of a 7-valent pneumococcal conjugate vaccine among Navajo and White Mountain Apache (N/WMA) children (abstract 1371). In: Abstracts of the Society for Pediatric Research, Baltimore, MD, USA. 2001.

55. Briles D.E., Hollingshead S., Brooks-Walter A., et al. The potential to use PspA and other pneumococcal proteins to elicit protection against pneumococcal infection. Vaccine 2000; 18:1707-11.

56. Brooks-Walter A., Briles D.E., Hollingshead S.K. The pspC gene of Streptococcus pneumoniae encodes a polymorphic protein, PspC, which elicits crossreactive antibodies to $\mathrm{PspA}$ and provides immunity to pneumococcal bacteremia. Infect Immun. 1999;67:6533-42.

57. McDaniel L.S., Waltman W.D. 2nd, Gray B., Briles D.E. A protective monoclonal antibody that reacts with a novel antigen of pneumococcal teichoic acid. Microb Pathog 1987;3:249-60.

58. Briles D.E., Hollingshead S.K., Swiatlo E., et al. PspA and PspC: Their potential for use as pneumococcal vaccines. Microb Drug Resist 1997;3:401-8.

59. Hollingshead S.K., Becker R., Briles D.E. Diversity of PspA: Mosaic genes and evidence for past recombination in Streptococcus pneumoniae. Infect Immun 2000;68:5889-900.

60. Briles D.E., Hollingshead S.K., King J., et al. Immunization of humans with recombinant pneumococcal surface protein A (rPspA) elicits antibodies that passively protect mice from fatal infection with Streptococcus pneumoniae bearing heterologous PspA. J Infect Dis 2000;182:1694-1701.
61. Greenwood B.M. The epidemiology of acute bacterial meningitis in tropical Africa. In: Williams J.D., Burnie J. [eds]. Bacterial meningitis. London: Academic Press, 1987: p61-91.

62. Schwartz B., Moore P.S., Broome C.V. Global epidemiology of meningococcal disease. Clin Microbiol Rev 1989;2 Suppl:S118-24.

63. Gotschlich E.C., Goldschneider I., Artenstein M.S. Human immunity to the meningococcus. IV: Immunogenicity of group A and group C meningococcal polysaccharides in human volunteers. J Exp Med 1969; $129: 1367-84$.

64. Zollinger W.D. In: Levine M.M., Woodrow G.C., Kaper J.B., et al. (eds). New Generation Vaccines. Deker, New York, 1997, p. 469.

65. Fairley C.K., Begg N., Borrow R., et al. Conjugate meningococcal serogroup $\mathrm{A}$ and $\mathrm{C}$ vaccine: Reactogenicity and immunogenicity in United Kingdom infants. J Infect Dis 1996; 174:1360-3.

66. Twumasi P.A. Jr., Kumah S., Leach A., et al. A trial of a group A plus group $\mathrm{C}$ meningococcal polysaccharideprotein conjugate vaccine in African infants. J Infect Dis 1995; 171:632-8.

67. Bramley J.C., Hall T., Finn A., et al. Safety and immunogenicity of three lots of meningococcal serogroup $\mathrm{C}$ conjugate vaccine administered at 2, 3 and 4 months of age. Vaccine 2001;19:2924-31.

68. English M., MacLennan J.M., Bowen-Morris J.M., et al. A randomised, double-blind, controlled trial of the immunogenicity and tolerability of a meningococcal group $\mathrm{C}$ conjugate vaccine in young British infants. Vaccine 2000; 19:1232-8.

69. MacLennan J.M., Shackley F., Heath P.T., et al. Safety, immunogenicity, and induction of immunologic memory by a serogroup $\mathrm{C}$ meningococcal conjugate vaccine in infants: A randomized controlled trial. JAMA 2000;283:2795-801.

70. Rennels M.B., Edwards K.M., Keyserling H.L., et al. Safety and immunogenicity of four doses of Neisseria meningitidis group C vaccine conjugated to CRM197 in United States infants. Pediatr Infect Dis J 2001;20:153-9.

71. Pan American Health Organization. Meningococcal conjugate vaccines for África (abstract page 21). In: Abstracts of Conference on Vaccines, Prevention and Public Health: A vision for the future. Washington, DC, USA: PAHO, 2002.

72. Rappuoli R. Conjugates and reverse vaccinology to eliminate bacterial meningitis. Vaccine 2001;19:2319-22.

73. Balmer P., Borrow R., Miller E. Impact of meningococcal C conjugate vaccine in the UK. J Med Microbiol 2002;51:717-22. 
74. Trotter C.L., Ramsay M.E., Kaczmarski E.B. Meningococcal serogroup $\mathrm{C}$ conjugate vaccination in England and Wales: Coverage and initial impact of the campaign. Common Dis Public Health 2002;5:220-5.

75. Morbidity Mortality Weekly Report. Summary of notifiable diseases, United States, 1998. Available: $\underline{\text { http:/ }}$ /www.cdc.gov/mmwr/PDF/wk/mm4654.pdf. Accessed 13 January 2003.

76. Scholten R.J., Bijlmer H.A., Poolman J.T., et al. Meningococcal disease in The Netherlands, 19581990: A steady increase in the incidence since 1982 partially caused by new serotypes and subtypes of Neisseria meningitidis. Clin Infect Dis 1993; 16 :237-46.

77. Finne J., Bitter-Suermann D., Goridis C., Finne U. An IgG monoclonal antibody to group B meningococci crossreacts with developmentally regulated polysialic acid units of glycoproteins in neural and extraneural tissues. J Immunol 1987; 138:4402-7.

78. Hayrinen J., Jennings H., Raff H.V., et al. Antibodies to polysialic acid and its $\mathrm{N}$-propyl derivative: Binding properties and interaction with human embryonal brain glycopeptides. J Infect Dis 1995; 171:1481-90.

79. Bjune G., Hoiby E.A., Gronnesby J.K., et al. Effect of outer membrane vesicle vaccine against group B meningococcal disease in Norway. Lancet 1991;338:1093-6.

80. Moraes J.C., Perkins B.A., Camargo M.C., et al. Protective efficacy of a serogroup B meningococcal vaccine in Sao Paulo, Brazil. Lancet 1992;340:1074-8.

81. Noronha C.P., Struchiner C.J., Halloran M.E. Assessment of the direct effectiveness of BC meningococcal vaccine in Rio de Janeiro, Brazil: A case-control study. Int Epidemiol 1995;24:1050-7.

82. Tappero J.W., Lagos R., Ballesteros A.M., et al. Immunogenicity of 2 serogroup B outer-membrane protein meningococcal vaccines: A randomized controlled trial in Chile. JAMA 1999;281:1520-7.

83. Poolman J.T. Development of a meningococcal vaccine. Infect Agents Dis 1995;4:13-28.

84. Pizza M., Scarlato V., Masignani V., et al. Identification of vaccine candidates against serogroup B meningococcus by whole-genome sequencing. Science 2000;287:1816-20.

85. Tettelin H., Saunders N.J., Heidelberg J., et al. Complete genome sequence of Neisseria meningitidis serogroup B strain MC58. Science 2000;287:1809-15.

86. Adderson E.E., Byington C.L., Spencer L., et al. Invasive serotype a Haemophilus influenzae infections with a virulence genotype resembling Haemophilus influenzae type b: Emerging pathogen in the vaccine era? Pediatrics 2001;108:E18.
87. Cerquetti M., Ciofi degli Atti M.L., Renna G., et al. Characterization of non-type $\mathrm{b}$ Haemophilus influenzae strains isolated from patients with invasive disease. The HI Study Group. J Clin Microbiol 2000;38:4649-52.

88. Hausdorff W.P., Siber G., Paradiso P.R. Geographical differences in invasive pneumococcal disease rates and serotype frequency in young children. Lancet 2001;357:950-2.

89. Waggoner-Fountain L.A., Hendley J.O., Cody E.J., et al. The emergence of Haemophilus influenzae types e and $\mathrm{f}$ as significant pathogens. Clin Infect Dis 1995;21:1322-4.

90. Booy R., Heath P.T., Slack M.P., et al. Vaccine failures after primary immunisation with Haemophilus influenzae type-b conjugate vaccine without booster. Lancet 1997;349:1197-202.

91. Breukels M.A., Spanjaard L., Sanders L.A., Rijkers G.T. Immunological characterization of conjugated Haemophilus influenzae type b vaccine failure in infants. Clin Infect Dis 2001;32:1700-5.

92. Andrade A.L.S.S., Brandileone M.C., DiFabio J.L., et al. Haemophilus influenzae resistance in Latin America: Systematic review of surveillance data. Microb Drug Resist 2001; 7:375-89.

93. Brandileone M.C., DiFabio J.L., Vieira V.S., et al. Geographic distribution of penicillin resistance of Streptococcus pneumoniae in Brazil: Genetic relatedness. Microb Drug Resist 1998;4:209-17.

94. Galil K., Singleton R., Levine O.S., et al. Reemergence of invasive Haemophilus influenzae type b disease in a well-vaccinated population in remote Alaska. J Infect Dis 1999; 179:101-6.

95. Gazagne L., Delmas C., Bingen E., Dabernat H. Molecular epidemiology of ampicillin-resistant non-betalactamase-producing Haemophilus influenzae. J Clin Microbiol 1998;36:3629-35.

96. Ko A.I., Reis J.N., Coppola S.J., et al. Clonally related penicillin-nonsusceptible Streptococcus pneumoniae serotype 14 from cases of meningitis in Salvador, Brazil. Clin Infect Dis 2000;30:78-86.

97. Sader H.S., Gales A.C., Granacher T.D., et al. Prevalence of antimicrobial resistance among respiratory tract isolates in Latin America: Results from SENTRY antimicrobial surveillance program (1997-98). Braz J Infect Dis 2000;4:24554.

98. Wolf B., Rey L.C., Brisse S., et al. Molecular epidemiology of penicillin-resistant Streptococcus pneumoniae colonizing children with community-acquired pneumonia and children attending day-care centres in Fortaleza, Brazil. J Antimicrob Chemother 2000;46:757-65.

99. Woods C.W., Armstrong G., Sackey S.O., et al. Emergency vaccination against epidemic meningitis in Ghana: Implications for the control of meningococcal disease in West Africa. Lancet 2000;355:30-3. 